\title{
Crowdsourcing e suas Práticas Colaborativas: Novas Possibilidades para o Ensino e Aprendizagem do Design
}

\author{
Crowdsourcing and its Collaborative Practices: New Possibilities for Design Teaching \\ and Learning
}

MORAES, Mateus Braga; Graduando em Design de Produto; Universidade Positivo mat.231098@gmail.com

OLIVEIRA, Alexandre Antonio; Mestre; Universidade Positivo

alexandre.oliveira@up.edu.br

\section{Resumo}

Este artigo visa estudar as novas práticas do Design e como aliá-las às práticas do ensino. Com o suporte do Crowdsourcing e por meio de uma plataforma o designer pode ter acesso direto a diversos stakeholders no desenvolvimento de novas ideias. Este estudo faz o levantamento das práticas de Crowdsourcing para o Design, mapeia as empresas e plataformas nacionais e internacionais que usufruem desta prática e relaciona tais atividades às competências e práticas projetuais discentes. Com isso, podemos observar diversas ramificações destas novas práticas digitais e novas formas de aprendizado, criando assim um novo modo de integrar os designers a este novo sistema de desenvolvimento e criação.

Palavras Chave: crowdsourcing; ensino; plataformas.

\begin{abstract}
This article aims to study the new Design practices and how to combine them with teaching practices. With the support of Crowdsourcing and through a platform the designer can have direct access to diverse stakeholders in the development of new ideas and products. This study surveys the practices of Crowdsourcing for Design, maps the companies, the national and international platforms that uses this practice and relates these activities to the skills and practices of design students. With this, we can observe several ramifications of these new digital practices and new forms of learning, thus creating a new way of integrating the designers to this new system of development and creation.
\end{abstract}

Keywords: crowdsourcing; education; platform. 


\section{Introdução}

Esse estudo é focado nas possíveis aplicações das plataformas de crowdsourcing para o sistema de ensino e o modo que estudantes e designers podem aperfeiçoar sua prática profissional por meio desta atividade.

Na prática profissional do Design observa-se a ascensão de novos modelos de projeto que aproveitam as possibilidades da internet no processo de comunicação entre os vários stakeholders ${ }^{1}$. Uma destas abordagens é o Crowdsourcing. De acordo com Zhong et al. (2017), ela é uma prática de inovação aberta e consiste em duas palavras: terceirização e multidão. Ela visa beneficiar-se dos esforços e idéias de uma multidão virtual através de tecnologias da internet (ZHONG et al, 2017). Neste estudo, focamos no Crowdsourcing no Processo de Desenvolvimento de Ideias e Produtos e como essas práticas podem conectar as competências do designer aos diversos stakeholders neste processo.

De acordo com a revista Forbes (2015), seis das nove empresas mais valiosas do mundo usam ou usaram o crowdsourcing como fonte criativa para ideias e soluções por meio de plataformas: McDonald's, IBM, Coca-Cola, Google, General Electric e Microsoft (ROTH, 2012). Empresas como Lego (LEGO IDEAS, 2017) e Dell (IDEASTORM, 2017) têm plataformas próprias de crowdsourcing ou contratam serviços para desenvolver tais práticas.

Outro exemplo é o crescimento de faturamento que o Crowdfunding, outra modalidade de crowdsourcing (que usa da multidão para o financiamento de projetos e novas ideias) gerou nos Estados Unidos: 919 milhões no ano de 2017 e em 2018 este mercado irá movimentar mais de 1 bilhão de dólares (STATISTA 2017).

O ensino e aprendizagem do Design está passando por uma rápida evolução com mais estudantes fazendo uso dos recursos da internet e suas ferramentas, como os serviços de impressão 3D e crowdsourcing, para desenvolver e validar suas ideias mais rapidamente (CHANG, 2015). Trazendo o contexto emergente desta prática em diversos projetos de Design (BATTISTELLA; NONINO, 2012) é preemente que a educação em Design, em nível de graduação, deva providenciar e simular o contexto da prática profissional aos seus alunos. Em uma revisão de literatura preliminar acerca do tema (crowdsourcing e educação), nenhum texto foi encontrado nas bases de dados ScienceDirect (2017) e no Portal de Periódicos CAPES (2017) abordando o ensino de crowdsourcing no Design, em contrapartida, diversos artigos salientam a utilidade de tal prática para o desenvolvimento de ideias e soluções na área (OLIVEIRA, 2017; DICKIE et. al, 2014; SHOYAMA et. al, 2014). Desta forma, é necessária a implementação de atividades e disciplinas que trazem as práticas e o contexto contemporâneo do Design.

\footnotetext{
${ }^{1}$ Stakeholder: Uma pessoa como um funcionário, cliente ou cidadão envolvido com uma organização, sociedade, etc. e, portanto, tem responsabilidades para ele e um interesse em seu sucesso. (CAMBRIDGE DICTIONARY, 2018)
} 


\section{Revisão de Literatura}

Crowdsourcing é definido pelo ato de uma empresa ou instituição terceirizar (ou fazer um convite aberto) para uma rede de pessoas para a realização de uma determinada tarefa (ESTELLÉSAROLAS; GONZALEZ-LADRÓN-DE-GUEVARA, 2012). Este termo, cunhado em 2006 por Jeff Howe em uma matéria para a revista Wired, é caracterizado por trabalhar com a multidão (por isso o termo crowd). Nesta multidão, a rede é indefinida ou definida, geralmente anônima e cada participante pode agir isoladamente (BENKLER, 2006). Crowdsourcing é uma maneira das organizações aumentarem a diversidade e criatividade em seus processos por meio da quantidade maior de pessoas atuando (GRACE et al., 2015).

Alguns autores citam o desenvolvimento de produtos e suas tarefas através desta modalidade do crowdsourcing. Djelassi e Decoopman (2013) cita que essa prática no desenvolvimento de ideias e produtos nas empresas primeiramente consiste em integrar o consumidor (ou desenvolvedor externo) em seu processo de inovação. Os mesmos autores também defendem que os gerentes das empresas não devem apenas ver esta prática como uma ferramenta de marketing para promoção, mas um processo complexo de inovação que pode oferecer acesso a um espectro maior de capacidade de inovação.

Esta nova relação de desenvolvimento com a multidão pode mudar a relação com que o designer interaja com o desenvolvimento de novos produtos e soluções. De acordo com Andrade (2013) em sua análise no uso e na contribuição do Design nos métodos convencionais no processo de desenvolvimento de novos produtos (PDP) nas empresas, o Design tem a capacidade de permear todas as etapas, seja exercendo função principal em certos momentos e em outros atuando como função de apoio. Neste caso do PDP via crowdsourcing, vemos mais nitidamente a função de apoio e de tomada de decisões no projeto. Oliveira (2017) elabora em sua dissertação diversos papéis que o designer pode atuar no PDP via crowd-design.

Além do crowdsourcing, foram buscadas práticas com base na multidão para diferentes tipos de submissões e modalidades. Abaixo segue a tabela com as respectivas modalidades e definições encontradas: 
Tabela 01 - Tipos de Crowdsourcing

\begin{tabular}{lll}
\hline \multicolumn{1}{c}{ Tipo } & \multicolumn{1}{c}{ Atividades } & Autor(es) \\
\hline Crowdsourcing & $\begin{array}{l}\text { Crowdsourcing é o uso deliberado de multidões para resolver problemas, } \\
\text { criar novos produtos e melhorar as experiências do consumidor. Quando } \\
\text { usado por marcas, o crowdsourcing envolve os consumidores pedindo } \\
\text { que façam parte de um chamado deliberado para a ação. }\end{array}$ & Bal \\
\hline Crowd-design & $\begin{array}{l}\text { Modalidade emergente do sistema de projeto e produção que utiliza os } \\
\text { conhecimentos e recursos disponíveis na multidão, geralmente através } \\
\text { da internet, com o propósito de resolver problemas e/ou criar conteúdo. }\end{array}$ & $\begin{array}{l}\text { Oliveira (2017) } \\
\text { apud Dickie et al. } \\
\text { (2014) }\end{array}$ \\
\hline Crowdfunding & $\begin{array}{l}\text { Processo de fazer um projeto que precisa de investimento, e solicitar a } \\
\text { um grande grupo de pessoas que forneçam este investimento. }\end{array}$ & Forbes (2017) \\
\hline Crowdlabor & $\begin{array}{l}\text { Processo que aproveita-se da larga distribuição de trabalho disponível } \\
\text { online para cumprir uma série de tarefas, das simples até as mais } \\
\text { complexas. }\end{array}$ & $\begin{array}{l}\text { Crowdsourcing.org } \\
\text { (2014) }\end{array}$ \\
\hline Crowdcreativity & $\begin{array}{l}\text { Processo que aproveita o grande número de talentos criativos para } \\
\text { projetar e desenvolver arte original, mídia ou conteúdo. É usado em } \\
\text { comunidades online para desenvolver produtos e conceitos originais, } \\
\text { incluindo fotografia, publicidade, cinema, produção de vídeo, design } \\
\text { gráfico, vestuário, bens de consumo e conceitos } \\
\text { de branding. }\end{array}$ & $\begin{array}{l}\text { Crowdsourcing.org } \\
\text { (2014) }\end{array}$ \\
\hline Crowdstorm & $\begin{array}{l}\text { Processo utilizado para gerar ideias. É realizado online e feito pela } \\
\text { multidão. Podendo ainda ser simples, que apenas demanda soluções } \\
\text { para um determinado problema, e mais complexo onde as pessoas } \\
\text { podem interferir nas soluções dadas por outras pessoas, construindo } \\
\text { idéias maiores e melhores. }\end{array}$ & $\begin{array}{l}\text { Abrahamson } \\
\text { (2013) }\end{array}$ \\
\hline
\end{tabular}

Fonte: dos autores (2018)

A partir das definições sobre as práticas de crowdsourcing, foram pesquisadas as naturezas de suas plataformas para dar base à investigação.

\subsection{Plataformas de Crowdsourcing}

Battistella e Nonino (2012) definem as plataformas de inovação aberta como um instrumento de agregação e integração de diferentes membros (indivíduos e organizações) em uma comunidade. Nesta definição se encaixam as plataformas de crowdsourcing. Oliveira (2017, p. 29) afirma que com as plataformas as empresas buscam as melhores maneiras para "possibilitar e melhorar estes processos de inovação dando acesso a instrumentos disponíveis na Internet para que mais agentes externos consigam interagir com suas atividades".

As plataformas de crowdsourcing têm diversas naturezas quanto à sua participação e colaboração. Wu et al. (2015) salienta que a escolha da plataforma deve refletir a natureza das tarefas que serão propostas. Hosseini et al. (2014), em estudo taxonômico do crowdsourcing identificou algumas características e dinâmicas das plataformas em relação aos participantes, organizadores e à tarefa que será executada, segue abaixo um quadro: 
Tabela 02 - Características Gerais das Plataformas e Suas Dinâmicas

\begin{tabular}{|c|c|c|c|}
\hline $\begin{array}{c}\text { Interações Relacionadas à } \\
\text { Multidão } \\
\end{array}$ & $\begin{array}{c}\text { Interações Relacionadas ao } \\
\text { Organizador } \\
\end{array}$ & $\begin{array}{c}\text { Facilidades Relacionadas à } \\
\text { Tarefa } \\
\end{array}$ & $\begin{array}{c}\text { Facilidades Relacionadas à } \\
\text { Plataforma } \\
\end{array}$ \\
\hline Deve fornecer inscrição & Deve fornecer inscrição & \multirow{2}{*}{ - Agregar resultados } & \multirow{2}{*}{ Ambiente online } \\
\hline Deve fornecer autenticação & Deve fornecer autenticação & & \\
\hline $\begin{array}{l}\text { Deve fornecer declaração } \\
\text { de habilidades }\end{array}$ & $\begin{array}{l}\text { Deve fornecer transmissão } \\
\text { de tarefa }\end{array}$ & \multirow{2}{*}{$\begin{array}{l}\text { Esconder o resultado de } \\
\text { outros participantes }\end{array}$} & $\begin{array}{l}\text { Gerenciar erros de uso da } \\
\text { plataforma }\end{array}$ \\
\hline $\begin{array}{l}\text { Deve fornecer atribuição de } \\
\text { tarefas }\end{array}$ & Deve fornecer assistência & & \multirow{3}{*}{$\begin{array}{l}\text { Deve fornecer facilidade de } \\
\text { uso }\end{array}$} \\
\hline Deve fornecer assistência & $\begin{array}{l}\text { Deve fornecer negociação } \\
\text { de tempo }\end{array}$ & \multirow{2}{*}{$\begin{array}{l}\text { Armazenar histórico de } \\
\text { tarefas completadas }\end{array}$} & \\
\hline $\begin{array}{l}\text { Deve fornecer submissão de } \\
\text { resultados }\end{array}$ & $\begin{array}{l}\text { Deve fornecer negociação } \\
\text { de preço }\end{array}$ & & \\
\hline Coordenar multidão & $\begin{array}{l}\text { Deve fornecer verificação } \\
\text { de resultado }\end{array}$ & $\begin{array}{l}\text { Deve fornecer parâmetros } \\
\text { de qualidades }\end{array}$ & Deve fornecer interação \\
\hline Supervisionar multidão & \multirow{2}{*}{$\begin{array}{l}\text { Deve fornecer ciclos de } \\
\text { comentários }\end{array}$} & \multirow{2}{*}{$\begin{array}{l}\text { Deve fornecer limite de } \\
\text { quantidade }\end{array}$} & \multirow{2}{*}{$\begin{array}{l}\text { Deve fornecer mecanismos } \\
\text { de pagamento }\end{array}$} \\
\hline $\begin{array}{l}\text { Deve fornecer ciclos de } \\
\text { comentários }\end{array}$ & & & \\
\hline
\end{tabular}

Fonte: Oliveira (2017)

Certas plataformas de desenvolvimento como a Innonatives ${ }^{2}$, Innocentive ${ }^{3}$ e NineSigma $^{4}$ possuem comunidades especializadas de usuários engajados em resolver problemas e pode suprir a necessidade de empresas que não consigam estruturar equipes para estes tipos de atividades criativas, como aponta Oliveira (2017).

\subsection{Diretriz Curricular Nacional para o Ensino do Design no Brasil}

De acordo com a Resolução CNE/CES 5 (2004) do Ministério de Educação e Cultura (MEC), que estabelece regras e diretrizes para abertura e oferta dos cursos de Design em todo o território nacional, qualquer curso de graduação em Design na sua formação discente deve:

"ensejar, como perfil desejado do formando, capacitação para a apropriação do pensamento reflexivo e da sensibilidade artistica, para que o designer seja apto a produzir projetos que envolvam sistemas de informações visuais, artisticas, estéticas culturais $e$ tecnólogicas, observados o ajustamento histórico, os traços culturais e de desenvolvimento das comunidades bem como as características dos usuários e de seu contexto sócioeconômico e cultural." (RES. CNE/CES 5/2004. DOI, Brasília, 15 de março de 2004, Seção 1, p. 24).

2 Innonatives é uma plataforma de crowdsourcing especializada em soluções para a sustentabilidade. Um projeto nesta plataforma prevê o uso de crowdsourcing, crowdfunding e crowdvoting para a viabilização do mesmo. Site: www.innonatives.com.

3 Plataforma de crowdsourcing de ideias e soluções inovadoras. Mais voltado para soluções no campo da engenharia e ciências exatas, mas admite desafios de ideias para produtos. Site: www.innocentive.com

4 Plataforma de crowdsourcing no qual o desenvolvimento de novos produtos é dividido em duas categorias competição para novas ideias ou aceleração de um desenvolvimento já existente. Site: www.ninesigma.com. 
Para o estabelecimento de diretrizes, competências desejadas do egresso do curso de Design e das suas habilitações, a resolução CNE/CES 5/2004 se divide em 13 artigos. Para fins de categorização e complementação do perfil do formando com as atividades de crowdsourcing nesta pesquisa, foram separados tais artigos:

- $\quad$ Artigo 40 (parágrafos I a VIII): revela as competências e habilidades do discente a ser formado por um curso de Design;

- $\quad$ Artigo 5o (parágrafo II): delimita conteúdos específicos para possíveis habilitações no campo do Design.

$\mathrm{O}$ artigo 4 으, que centraliza essas habilidades e competências desejadas, é dividida em 8 competências. Para fins de categorização nesta pesquisa, a divisão se manteve a partir de tais competências da resolução, listadas da seguinte forma (negritos feitos pelos autores para evidenciar as categorias propostas nesse trabalho):

1. capacidade criativa para propor soluções inovadoras, utilizando domínio de técnicas e de processo de criação;

2. capacidade para o domínio de linguagem própria expressando conceitos e soluções, em seus projetos, de acordo com as diversas técnicas de expressão e reprodução visual;

3. capacidade de interagir com especialistas de outras áreas de modo a utilizar conhecimentos diversos e atuar em equipes interdisciplinares na elaboração e execução de pesquisas e projetos;

4. visão sistêmica de projeto, manifestando capacidade de conceituá-lo a partir da combinação adequada de diversos componentes materiais e imateriais, processos de fabricação, aspectos econômicos, psicológicos e sociológicos do produto;

5. domínio das diferentes etapas do desenvolvimento de um projeto, a saber: definição de objetivos, técnicas de coleta e de tratamento de dados, geração e avaliação de alternativas, configuração de solução e comunicação de resultados;

6. conhecimento do setor produtivo de sua especialização, revelando sólida visão setorial, relacionado ao mercado, materiais, processos produtivos e tecnologias abrangendo mobiliário, confecção, calçados, jóias, cerâmicas, embalagens, artefatos de qualquer natureza, traços culturais da sociedade, softwares e outras manifestações regionais;

7. domínio de gerência de produção, incluindo qualidade, produtividade, arranjo físico de fábrica, estoques, custos e investimentos, além da administração de recursos humanos para a produção;

8. visão histórica e prospectiva, centrada nos aspectos sócio-econômicos e culturais, revelando consciência das implicações econômicas, sociais, antropológicas, ambientais, estéticas e éticas de sua atividade. 
Por último, também foram levantadas as habilitações que são delimitadas nesta mesma resolução, no artigo 5으, parágrafo II, para a abertura de cursos de Design específicos. Desta forma, além das competências a serem desenvolvidas, também poderão ser relacionadas as habilitações que cada plataforma de crowdsourcing poderá auxiliar na formação específica de cada discente. A categorização das habilitações ficou desta forma:

1. produções artisticas;

2. produção industrial;

3. comunicação visual;

4. interface;

5. modas e vestuários;

6. interiores e paisagismos;

7. design e outras produções artisticas que revelem adequada utilização de espaços e correspondam a níveis de satisfação pessoal (serviços, sistemas produto-serviço, etc).

Para fins de nomenclatura e simplificação, a sétima categoria das habilitações nos resultados será nomeada como "Serviço".

O cruzamento das competências e habilitações com as modalidades das plataformas de crowdsourcing estão delineados e categorizados na seção de Resultados e Discussões desta pesquisa.

\section{Objetivos}

A seguir são descritos os objetivos geral e específicos desta pesquisa.

\subsection{Objetivo Geral}

Discutir como o crowdsourcing e suas plataformas podem complementar na formação do discente brasileiro do curso superior de Design a partir de suas habilitações e competências.

\subsection{Objetivos Específicos}

1. Classificar os tipos de crowdsourcing usados no desenvolvimento de novos produtos e ideias por meio de levantamento bibliográfico;

2. Identificar empresas e plataformas que usufruem desta prática colaborativa no desenvolvimento de novos produtos e ideias por meio de pesquisa baseada na rede;

3. Classificar a natureza do desenvolvimento e hablitações de acordo com as diretrizes curriculares para o ensino do Design estabelecidas na Resolução CNE/CES 5 (2004);

4. Apresentar plataformas de crowdsourcing que podem auxiliar na formação do discente de Design e na sua prática profissional nas empresas a partir das modalidade e categorizá-las a partir das modalidades e habilitações. 


\section{Metodologia}

$\mathrm{Na}$ primeira etapa foi feito um levantamento bibliográfico acerca das práticas do crowdsourcing e quais empresas usufruem desta prática, adquirindo assim diversas descrições e definições dos fenômenos. A pesquisa foi realizada de maneira assistemática na base de dados ScienceDirect (2017). Todos os artigos utilizados na pesquisa primaram por três principais filtros: Artigos concluídos entre 2015-2018; revisados por pares; e na língua portuguesa ou inglesa. As palavras-chaves usadas na pesquisa foram: "crowdsourcing"; "crowdsourcing+design"; "crowdsourcing+product"; e "crowd+platform". Abaixo segue a lista com o número de artigos pesquisados:

Tabela 02- Número de Artigos das Plataformas Science Direct

\begin{tabular}{|c|c|c|c|c|}
\hline Palavras-chaves & $\begin{array}{l}\text { № de artigos } \\
\qquad(2015)\end{array}$ & $\begin{array}{l}\text { № de artigos } \\
\qquad(2016)\end{array}$ & $\begin{array}{l}\text { № de artigos } \\
\qquad(2017)\end{array}$ & $\begin{array}{c}\text { № de artigos } \\
(2018)\end{array}$ \\
\hline Crowdsourcing & 629 & 759 & 946 & 524 \\
\hline Crowdsourcing + Design & 511 & 595 & 775 & 443 \\
\hline Crowdsourcing + Product & 335 & 382 & 485 & 267 \\
\hline Crowd + Platform & 380 & 478 & 607 & 343 \\
\hline Total de artigos selecionados & 1 & 1 & 2 & 1 \\
\hline
\end{tabular}

Fonte: dos autores (2018)

O levantamento feito nas bases supracitadas revelaram um aumento no número de publicações ao longo dos anos de 2015 a 2017 para todos os termos. Para a seleção dos artigos para a leitura, foram separados aqueles que eram pertinentes ao tema da pesquisa (crowdsourcing no desenvolvimento de produtos e ideias para a complementação de habilidades do designer, plataformas de crowdsourcing e suas tipologias) totalizando o número de 5 artigos (HOSSEINI et al., 2015; BARUCH et al., 2016; ZHONG e XINGZHENG, 2017; BAL et al., 2017; NETO e SANTOS, 2018).

A seguinte etapa foi levantar as diretrizes do MEC para graduação em Design que estabelecem as habilitações para os cursos e as competências que devem ser desenvolvidas pelo discente em sua trajetória educacional. Tais habilitações foram categorizadas a partir do levantamento feito acerca da Resolução CNE/CES 5 de 2004. A própria diretriz curricular nacional divide em oito categorias as habilitações (explicitados no tópico 2.1) e estas mesmas foram utilizadas no presente trabalho. Ademais, para fins de reconhecimento de habilidades do discente, também foram categorizadas suas competências. Tais competências foram divididas em sete categorias assim como a diretriz curricular nacional as divide. Com isso, pôde-se fazer a relação das práticas do Design e as plataformas que proporcionam o desenvolvimento coletivo.

Após reconhecer os diferentes termos de crowdsourcing a partir do levantameto biliográfico e as habilitações e competências em desenvolvimento no curso de Design no Brasil a 
partir da diretriz curricular nacional, foram pesquisadas as diferentes empresas que operam com as plataformas, resultando em 64 plataformas. Tal pesquisa foi baseada primeiramente nas citações em artigos e posteriormente em pesquisas baseadas na rede.

O levantamento das atividades das plataformas foi feito a partir dos projetos em andamento e resultados prévios que as mesmas tinham em seu histórico. Analisou-se se cada plataforma constava o desenvolvimento baseado em rede com abertura de desafios ou tarefas e se possibilitava a livre submissão de ideias pela multidão, como aponta Wu et al. (2014). Confirmadas tais características, foram definidos em quais habilitações estas plataformas se encaixavam a partir da natureza de seus resultados projetuais e posteriormente quais hablidades eram desenvolvidas analisando as etapas que eram levadas em consideração para cada tarefa solicitada.

O resultado da pesquisa, tópico descrito a seguir, foi feito relacionando as plataformas, suas modalidades e suas atividades com as competências e habilitações. Esse será focado na sugestão de plataformas para complementação das atividades curriculares do ensino do Design.

\section{Resultados e Discussão}

A partir das definições feitas na Revisão de Literatura acerca das modalidades do crowdsourcing, foi possível adequar e relacionar as atividades detalhadas de acordo com as competências e habilidades que são requeridas para a formação do Designer, a partir da Resolução CNE/CES 5 (2004) do Ministério de Educação e Cultura (MEC).

Abaixo estão descritos os resultados alcançados dessa relação entre plataformas de crowdsourcing e as habilitações e competências do Design.

\subsection{Crowdsourcing como Complementação das Competências e Habilidades}

A primeira relação feita foi a das plataformas de crowdsourcing como complementação e desenvolvimento das competências e habilidades do discente durante o curso de Design. Em cada plataforma foi analisada as atividades requeridas para desenvolvimento e a modalidade de crowdsourcing da mesma. Lembrando que uma plataforma pode requerer mais de uma competência das oito que foram definidas.

O crowdsourcing e suas modalidades podem complementar em diversas habilidades delineadas pela Resolução CNE/CES 5 (2004). Um exemplo é a plataforma Kickstarter ${ }^{5}$, que dá suporte ao aluno para apresentar suas ideias. Para isso, ele deve demonstrar e ilustrar o processo, ter acesso à produção do produto e finalmente saber comercializar e vender a ideia para a comunidade.

Outro exemplo é a plataforma OpenIDEO que contempla as mesmas habilidades de desenvolvimento, mas tende a oferecer um projeto à comunidade oferecendo uma premiação. Nela, o aluno também deve manejar as técnicas de criação de alternativas, expressão visual, etapas de desenvolvimento e produção.

Ambas plataformas usadas como exemplo contemplam as mesmas habilidades e auxiliam as práticas projetuais. Contudo, na plataforma Kickstarter (2018) a ideia parte do desenvolvedor

\footnotetext{
${ }^{5}$ Kickstarter: é o maior site de financiamento coletivo do mundo e que busca apoiar projetos inovadores por meio de crowdfunding. Acesso em https://www.kickstarter.com/
} 
(aluno) para receber um investimento; já na plataforma OpenIDEO (2018) a empresa oferece o briefing à comunidade, ofertando o investimento, com o aluno sendo parte de sua equipe.

Outras plataformas requerem outras habilidades, como a 99designs ${ }^{6}$ que preza pela linguagem visual gráfica e a Betabrand 7 que abre o sua empresa no mercado de moda para alunos da área demonstrarem suas habilidades. Abaixo estão listadas as 6 plataformas mais citadas no levantamento bibliográfico ou proeminentes nas buscas baseadas na rede e suas relações de competências utilizadas das 64 encontradas e categorizadas pelos autores:

Tabela 03 - Relação das Plataformas com as Competências Utilizadas

\begin{tabular}{|c|c|c|c|}
\hline Plataforma & Endereço eletrônico & Modalidade & Competências utilizadas \\
\hline Kickstarter & https://www.kickstarter.com/ & Crowdfunding & $\begin{array}{l}\text { Criação de soluções inovadoras, Linguagem e } \\
\text { expressão visual, Etapas de desenvolvimento, } \\
\text { Fabricação }\end{array}$ \\
\hline Indiegogo & https://www.indiegogo.com/ & Crowdfunding & $\begin{array}{l}\text { Criação de soluções inovadoras, Linguagem e } \\
\text { expressão visual, Etapas de desenvolvimento, } \\
\text { Fabricação }\end{array}$ \\
\hline Crowdspring & https://www.crowdspring.com/ & Crowdsourcing & $\begin{array}{l}\text { Criação de soluções inovadoras, Linguagem e } \\
\text { expressão visual, Etapas de desenvolvimento }\end{array}$ \\
\hline OpenIDEO & https://openideo.com & Crowdcreativity & $\begin{array}{l}\text { Visão histórica e prospectiva, Etapas de } \\
\text { desenvolvimento, Criação de soluções } \\
\text { inovadoras, Linguagem e expressão Visual }\end{array}$ \\
\hline Betabrand & https://www.betabrand.com/ & Crowdfunding & $\begin{array}{l}\text { Criação de soluções inovadoras, Linguagem e } \\
\text { expressão visual, Etapas de desenvolvimento, } \\
\text { Fabricação, Conhecimento de setor produtivo }\end{array}$ \\
\hline 99designs & https://99designs.com.br/ & Crowdsourcing & $\begin{array}{l}\text { Linguagem e expressão visual, Criação de } \\
\text { soluções inovadoras }\end{array}$ \\
\hline
\end{tabular}

Fonte: dos autores (2018)

\subsection{Crowdsourcing para as Habilitações de Design}

A segunda relação foi a das plataformas de crowdsourcing com as 7 habilitações em Design delimitadas pela Resolução CNE/CES 5 (2004). A natureza de desenvolvimento da plataforma e seus resultados finais (ideias ou produtos) é que definem qual habilitação é condizente com a mesma.

Um exemplo é a área de atuação da plataforma Lego Ideas (2018), que preza pelo desenvolvimento de produtos Lego. Uma vez que ela permeia o desenvolvimento de produto em virtude de sua produção, esta plataforma está categorizada na habilitação de "Produção Industrial". A plataforma OpenIDEO (2018), que prima por desenvolvimento de produtos e projetos sociais está categorizada na habilitação de "Produção Industrial" e "Design e outras

\footnotetext{
6 99designs: é uma empresa de design gráfico que cria logotipos, sites, aplicativos, cartões de visita, capas de livros, envoltórios de veículos, folhetos, ilustrações e outros produtos a partir da sua base de usuários. Acesso em: $h$ ttps://en. 99designs.com.br/

${ }^{7}$ Betabrand: é uma empresa de varejo de vestuário e plataforma de crowdfunding. A empresa projeta, fabrica e lança novos produtos em quantidades limitadas a cada semana. Acesso em: https://www.betabrand.com/
} 
produções artísticas que revelem adequada utilização de espaços e correspondam a níveis de satisfação pessoal" ou "Serviço". Em suma, ambos os projetos são classificados na habilitação de produção industrial pois todos têm em comum o desenvolvimento de produtos industriais seriados.

A pesquisa conta com uma variedade de plataformas internacionais e nacionais. Um exemplo é a plataforma brasileira Camiseteria ${ }^{8}$ que trabalha com crowdvoting para gerar alternativas de ilustrações que podem resultar em camisetas e artigos decorativos (habilitação "Comunicação visual"). Neste caso é importante ressaltar que o discente pode desenvolver diversos projetos de naturezas similares em sites diferentes como Colab55 (2018), Threadless (2018), 99designs (2018), entre outros. Abaixo a relação das 9 plataformas mais citadas na revisão bibliográfica ou proeminentes nas buscas baseadas na rede e suas diferentes habilitações:

Tabela 04 - Relação das Plataformas com as Habilitações em Design

\begin{tabular}{|c|c|c|c|}
\hline Plataforma & Endereço eletrônico & Modalidade & Habilitação no Design \\
\hline Lego Ideas & https://ideas.lego.com/ & Crowdsourcing & Produção industrial \\
\hline Openideo & https://openideo.com & Crowdcreativity & Serviço, Produção Industrial \\
\hline Camiseteria & https://www.camiseteria.com/ & Crowdsourcing & Comunicação visual \\
\hline Colab55 & https://www.colab55.com/ & Crowdsourcing & $\begin{array}{l}\text { Comunicação visual, Produção Industrial, } \\
\text { Moda e vestuários }\end{array}$ \\
\hline Threadless & https://www.threadless.com/ & Crowdsourcing & $\begin{array}{l}\text { Moda e vestuários, Comunicação visual, } \\
\text { Produção industrial }\end{array}$ \\
\hline 99designs & https://99designs.com.br/ & Crowdsourcing & Comunicação visual, Interface \\
\hline Grabcad & https://grabcad.com & Crowdsourcing & Produção Industrial, Comunicação visual \\
\hline Indiegogo & https://www.indiegogo.com/ & Crowdfunding & Produção industrial \\
\hline Quirky & https://quirky.com/ & Crowdstorm & Produção Industrial \\
\hline
\end{tabular}

Fonte: dos autores (2018)

\section{Discussão}

Primeiramente, vê-se lacunas nas pesquisas em relação ao uso de plataformas digitais para o desenvolvimento de competências de designers, estudantes ou não.

Durante a pesquisa foi observado o grande número de plataformas para Design Visual e Gráfico e acredita-se que o maior motivo é a facilidade da troca de informações por não ser algo tangível ou de produção que exige maior entendimento de materiais e processos industriais.

Atualmente, a área do Design está sendo contemplada com diversas possibilidades de ferramentas digitais, logo, é visto que um grande desafio é não só levar esta informação a

\footnotetext{
8 Camiseteria: plataforma e loja de camisetas que disponibiliza para que usuários submetam suas artes e ilustrações para serem votadas por meio de crowdvoting. Se a arte for bem votada, a camiseta é produzida e vendida. Site: hyps://soupop.com.br/site/camiseteria
} 
discentes mas apontar a qualidade e usabilidade da ferramenta. Crowdsourcing deverá ser mostrado como algo que pode complementar o ensino e como um modo de criar, pois discentes podem ter acesso a diversos âmbitos de desenvolvimento e apresentar suas ideias, criações e métodos. Isto também contribui para que alunos procurem manter esse modo digital como seu estilo de vida profissional.

Esse modelo emergente de desenvolvimento de ideias e produtos, como referenciado na seção Metodologia, está em crescente ascensão no número de pesquisas e ainda vê-se de maneira ínfima em relação à investigações de seus métodos e práticas usadas no Design. A maioria dos dados coletados são de estudos de casos ou de práticas empíricas do mercado.

Com os resultados, é possível afirmar que a maioria das plataformas de crowdsourcing são internacionais e de língua inglesa. Portanto, para o discente que busca com tais plataformas complementar suas habilidades e práticas no campo do Design, é necessário o conhecimento e entendimento da língua em nível intermediário, pois requer a interpretação de textos e explicitação de resoluções e desenvolvimentos de forma textual.

Das plataformas analisadas, nota-se a proeminência das modalidades de crowdsourcing e crowdfunding. Sobre as competências desenvolvidas, a maioria das plataformas requer as atividades de "linguagem e expressão visual" e "criação de soluções inovadoras". Essa informação prévia indica que tais plataformas e empresas estão compartilhando informações à desenvolvedores externos para que estes interfiram na criação de novas ideias. Tal prática é tida como inovação aberta e pode definir novos horizontes na conduta profissional destes novos designers.

A habilitação menos contemplada dentre as 8 definidas foi a de "Interiores e Paisagismo" com apenas duas plataformas entre as 64 analisadas. Aqui, é ressaltado que não foram buscadas plataformas de arquitetura, o que poderia ter ampliado o escopo e gerado novos exemplos.

\section{Conclusão}

Perante os resultados, é conclusivo que carecem estudos sobre novas modalidades de desenvolvimento de ideias e produtos em relação ao ensino do Design, principalmente modalidades emergentes como o crowdsourcing.

A classificação das plataformas foi dada de maneira satisfatória em relação às competências e às habilitações de Design no Brasil. Para futuras pesquisas, sugere-se estudos em relação às práticas específicas de ensino e de projeto e quais plataformas poderiam beneficiar discentes e docentes para que a qualidade de profissionais seja cada vez melhor a partir de sua formação.

Outro tipo de classificação que se sugere seria por cursos de Design abertos pelo Brasil de acordo com habilitações específicas (partindo de grades curriculares, disciplinas, etc.).

Nota-se que o resultado da pesquisa salienta que ainda é pequeno o número de plataformas de crowdsourcing no Brasil no que tange desenvolvimento de novas ideias e produtos. Assim como dito na pesquisa, empresas do mundo todo têm se beneficiado com esta prática e vêse preemente que empresas brasileiras possam usufruir e ter mais capacidade inovativa com usuários-desenvolvedores por todo o território. 


\section{Referências}

99 DESIGNS. 99 Designs. Disponível em: <https://99designs.com.br>. Acesso em: 10/11/2017.

ABRAHAMSON, S; RYDER, P; UNTERBERG, B. Crowdstorm: the future of innovation, ideas and problem solving. New Jersey: John Wiley \& Sons, Inc., Hoboken, 2013.

ANDRADE, P. D. Análise do Uso do Design no Processo de Desenvolvimento de Produtos em Empresas Desenvolvedoras de Bens de Consumo. Porto Alegre, 138p. Dissertação (Mestrado em Design) - Programa de Pós-graduação em Design, Universidade Federal do Rio Grande do Sul, Porto Alegre, 2013.

Bal, A. S.; Weidner, K.; Hanna, R.; Mills, A. J. Crowdsourcing and Brand Control. Business Horizons, 60(2), 219-228. 2017.

BATTISTELLA, C.; NONINO, F. Open innovation web-based platforms: the impact of different forms of motivation on collaboration. Innovation Management Policy Practices, v.14 (4), pp. 557-576, 2012.

BENKLER, Y. The Wealth of Networks: How Social Production Transforms Markets and Freedom. Yale Univ. Press, 2006.

CAMBRIDGE. Dicionário Cambridge: definition of "stakeholder". Disponível em: <https:// dictionary.cambridge.org/pt/dicionario/ingles-portugues/ stakeholder>. Acesso em 10/11/2017.

CAPES. Portal de Periódicos, Teses e Dissertações. Disponível em: <http://periodicos.capes.gov.br/ >. Acesso em: 16/09/2017.

CHANG, J. The economics of crowdfunding. Mimeo, UCLA working paper. 2015.

COLAB55. Colab55 - Seu Hub de Arte e Design . Disponível em: <https://www.colab55.com>. Acesso em: 10/11/2017.

CONSELHO NACIONAL DE EDUCAÇÃO - CNE/CÂMARA DE EDUCAÇÃO SUPERIOR - CES. Resolução no5, de 8 março de 2004. Brasília: 2004. Disponível em: <http://portal.mec.gov.br/cne/arquivos/ pdf/rces05_04.pdf>. Acesso em: 10/09/2017.

CROWDSOURCING.ORG. Directory of Crowdsourcing Sites. Disponível em: <http:// www.reports.crowdsourcing.org/>. Acesso em: 07/09/2017.

DELL IDEASTORM. Dell Ideastorm. Disponível em: <http://www.ideastorm.com/>. Acesso em: 10/11/2017.

DICKIE, I.; SANTOS, A. Bases Para Entendimento Do Crowdsourcing E Sua Aplicação Em Projetos De Crowd-Design. 11을 Congresso Brasileiro de Pesquisa e Desenvolvimento em Design, vol.1, num. 4. p. 1256-1267, 2014.

DICKIE, I.; SANTOS, A; BOTTANELLI, G.; CUCCU, M. O Processo De Desenvolvimento De Produtos Via Crowd-Design: oportunidades para a sustentabilidade. 11 을 Congresso Brasileiro de Pesquisa e Desenvolvimento em Design, vol.1, num.4. p. 1268-1279, 2014.

DJELASSI, S.; DECOOPMAN, I. Customers' participation in product development through crowdsourcing: Issues and implications. In: Industrial Marketing Management, v. 42, n. 5, p. 683692, 2013.

ESTELLÉS-AROLAS, E.; GONZALEZ-LADRÓN-DE-GUEVARA, F. Towards an integrated crowdsourcing 
definition. Journal of Information Science, v. 38, n. 2, p. 189-200, 2012.

FORBES. The World's Most Valuable Brands - 2015 Ranking. Disponível em: <http:// www.forbes.com/powerful-brands/list/\#tab:rank>. Acesso em 07/01/2018.

FORBES. Guidelines for Successful Crowdfunding - 2017. Disponível em: <http:// www.sciencedirect.com/science/article/pii/S2212827117301178>. Acesso em 10/11/2017.

GOOGLE SCHOLAR. Google Scholar. Disponível em: <https://scholar.google.com.br>. Acesso em: 06/10/2017.

GRACE, K.; LOU MAHER,M.; PREECE, J.; YEH, T.; STANGLE, A.; BOSTON, C.; A Process Model for Crowdsourcing Design: A Case Study in Citizen Science. Design Computing and Cognition '14, p. 18. 2014.

HOSSEINI, M.; SHAHRI, A.; PALP, K.; TAYLOR, J.; ALI, R. Crowdsourcing: A taxonomy and systematic mapping study. Computer Science Review, v.17, pp. 43-69. 2015.

KICKSTARTER. Kickstarter. Disponível em: <https://www.kickstarter.com>. Acesso em: 10/11/2017.

LEGO IDEAS. Lego Ideas. Disponível em: <https://ideas.lego.com/>. Acesso em: 10/11/2017.

OLIVEIRA, A.; SANTOS, A. Fundamentos e estratégias para uma boa prática de Crowd-design em empresas no desenvolvimento de novos Produtos. 5th International Conference on Integration of Design, Engineering and Management for Innovation. 2015.

OLIVEIRA, A A. Crowd-design no desenvolvimento de produto nas empresas. Defesa em 30/01/2017. 183 f. Dissertação de mestrado. Universidade de Federal do Paraná. Curitiba, 2017.

OPENIDEO. OpenIDEO: Social Impact Powered By Design Thinking. Disponível em: <https:// www.openideo.com>. Acesso em: 06/02/2018.

ROTH, Y. The 6 Best Global Brands use creative crowdsourcing. Paris, 2012. Disponível em: <http://news.eyeka.net/2012/03/the-6-best-global-brands-usecreative-crowdsourcing>. Acesso em: 06/01/2018.

SCIENCE DIRECT. Portal de Periódicos Science Direct. Disponível em: <www.sciencedirect.com>. Acesso em: 06/10/2017.

SHOYAMA, T.; TRIAQUIM, J.; DICKIE, I.; SANTOS, A. Elaboração do desafio no processo de Crowd Design do projeto Sustainability Maker Brazil. Anais do 4o GAMPI Plural, 2014.

STATISTA. Statista - The portal for statistics. Disponível em: <https://www.statista.com/>. Acesso em: $10 / 11 / 2017$.

THREADLESS. Threadless. Disponível em: <https://www.threadless.com>. Acesso em: 06/10/2017.

ZHONG, L; XINGZHENG, A. The value co-creation modes selection based on crowdsourcing. International Conference on Service Systems and Service Management (ICSSSM), 2017. 